\title{
State of humoral immunity in lactating sows and suckling piglets
}

\author{
Aleksey G. Shakhov, Sergey V. Shabunin, Larisa Yu. Sashnina, Yuliya Yu. Vladimirova, \\ and Mariya Yu. Zheynes* \\ All-Russian Veterinary Research Institute of Pathology, Pharmacology and Therapy, 394087, \\ Voronezh, Russia
}

\begin{abstract}
The state of humoral immunity in lactating sows and its formation in suckling piglets in the conditions of a pig-breeding complex were studied. In sows after farrow, a high content of total immunoglobulins, the main classes of $\operatorname{IgG}, \operatorname{IgM}$ and IgA, the concentration of which decreased in a day, followed by an increase in serum as lactation continued was detected in the serum and colostrum. In piglets at birth, the content of total immunoglobulins and the main Ig isotypes was insignificant, and at the age of twenty-four hours, as a result of absorption of colostral immunoglobulins in the small intestine, their amount in the serum was the highest, followed by a decrease in the concentration of IgG and $\operatorname{IgA}$ until the end of the suckling period, and $\operatorname{IgM}$ - up to day 14 with a further increase in its content, indicating the formation of a primary immune response. It has been detected that the dominant class of immunoglobulins in the serum and colostrum of sows and the serum of piglets is $\mathrm{IgG}$, and in milk - IgA. An increase in the level of mediumdispersed circulating immune complexes $(\mathrm{C} 4 \%)$ and their relation to giant $(\mathrm{C} 3 \%) \mathrm{CICs}$ was revealed, associated with an increase of the antigenic load in sows in the second half of lactation as a result of immunization, in milk with a decrease in the content of the main classes of immunoglobulins, and in piglets, due to this, with a decrease in passive immunity.
\end{abstract}

\section{Introduction}

The viability of newborn piglets largely depends on the adequacy of intrauterine development and immune status. The immaturity of the immune system registered in them is compensated by passive immunity transmitted by immunoglobulins (antibodies) and cellular factors of colostrum (milk) protection from sows [1-4], the productive health of which is ensured by nutritious balanced feeding and optimal keeping conditions [5-8].

Lack of colostral immunity is a predisposing factor of infectious diseases development in newborns [9].

One of the most important functions of immunoglobulins (antibodies) is antigen binding and the formation of immune complexes, which should result in neutralization or elimination of the antigen [10]. Normally, circulating immune complexes (CICs) are

\footnotetext{
* Corresponding author: Zheynes@mail.ru
} 
rapidly eliminated from the blood. At the same time, CICs often play an important role in the pathogenesis of the disease, and their long-term circulation in the organism correlates with the duration and severity of the pathological process. This is especially true for small and medium CICs, an increase in the blood level of which may indicate a predisposition to the development of immunopathological states [10-12].

Due to the impossibility of differentiating the maternal classes of immunoglobulins present in the organism of newborns in the early postnatal period and synthesized by their own immune system, the detection of the level of the main Ig isotypes in dynamics will make it possible to judge the formation of humoral immunity in young animals.

The issues related to the formation of colostral immunity in suckling piglets and its dependence on the immune status of sows have been studied insufficiently.

The objective of the research was to study the state of humoral immunity in dynamics in lactating sows and suckling piglets.

\section{Materials and methods}

The research was carried out at the industrial pig-breeding complex of LLC 'Vishnevskoe', Verkhnekhavskiy rayon, Voronezh region, on crossbred sows (Large White + Landrace + Duroc) of the $3^{\text {rd }}$ farrow and piglets obtained from them.

The animals were kept under optimal microclimate parameters, taking into account their physiological state.

The sows and the piglets obtained from them were clinically observed until the weaning at the age of 28 days.

On day 7 after farrow, the sows were immunized against parvovirus infection and erysipelas with the inactivated Parvoruvax vaccine (Merial, France) and on day 14 - with the classical plague vaccine LK - VNIIVViM against cultured dry classical swine fever (Pokrovskiy plant of biopreparations).

The humoral link of immunity was assessed by the content of total immunoglobulins, $\mathrm{IgG}, \mathrm{IgM}$ and IgA, circulating immune complexes (CICs) in the colostrum (milk) and blood from the sows $(n=6)$ after farrow and in 1, 7, 14, 22 and 26 days, the blood of the piglets $(n=6)$ before drinking colostrum and at the specified time after birth on the basis of the Research Center of FSBSI "ARVRIPP\&T".

The content of total immunoglobulins ( $\mathrm{Ig}$ ) was determined in accordance with [13], circulating immune complexes (CICs) - 3.0\%, 3.5\%, and 4.0\% [14], the coefficient of CIC pathogenicity $(\mathrm{C} 4 / \mathrm{C} 3$ ratio) $[10]$.

The content of immunoglobulins (Ig) of A, M and G classes in the colostrum (milk) and serum was determined by the method of enzyme-linked immunosorbent assay (ELISA), followed by taking into account the results on the Uniplan-TM spectrophotometer in accordance with the approved instructions for the test systems of Cloud-Clone Corp (USA).

Statistical processing of the obtained data was carried out using the Statistica v6.1 program, the reliability assessment was performed according to the Student's criterion.

\section{Study results and discussion}

The clinical status of sows and piglets during the period of immunological studies was within normal limits.

In sows after farrow, the highest serum levels of total immunoglobulins and their main isotypes $\mathrm{IgG}, \mathrm{IgM}$ and $\mathrm{IgA}$ were recorded (Table 1). 
Table 1. Content of total immunoglobulins, classes of immunoglobulins and circulating immune complexes in the serum of sows.

\begin{tabular}{|c|c|c|c|c|c|c|}
\hline \multirow{2}{*}{ Indicators } & \multirow{2}{*}{$\begin{array}{l}\text { After } \\
\text { farrow }\end{array}$} & \multicolumn{5}{|c|}{ Periods after farrow (days) } \\
\hline & & 1 & 7 & 14 & 22 & 26 \\
\hline $\begin{array}{c}\text { Total Ig, } \\
\mathrm{mg} / \mathrm{ml}\end{array}$ & $49.9 \pm 2.78$ & $44.7 \pm 9.54$ & $42.7 \pm 1.31$ & $46.3 \pm 2.78$ & $52.7 \pm 3.01$ & $49.9 \pm 1.1$ \\
\hline $\begin{array}{c}\mathrm{IgG} \\
\mathrm{mg} / \mathrm{ml} / \%\end{array}$ & $\frac{20.7 \pm 1.15}{41.5 / 78.3^{x}}$ & $\frac{18.5 \pm 1.26}{41.3 / 79.6^{x}}$ & $\frac{19.3 \pm 1.52}{45.2 / 79.6^{x}}$ & $\frac{21.4 \pm 2.38}{46.2 / 80.6^{x}}$ & $\frac{22.6 \pm 1.14^{\times}}{42.9 / 81.1^{x}}$ & $\frac{22.9 \pm 2.17^{x}}{45.9 / 78.9^{x}}$ \\
\hline $\begin{array}{c}\mathrm{IgM}, \\
\mathrm{mg} / \mathrm{ml} / \%\end{array}$ & $\frac{3.21 \pm 0.19}{6.43 / 12.1^{x}}$ & $\frac{2.75 \pm 0.08}{6.15 / 11.8^{x}}$ & $\frac{2.89 \pm 0.12}{6.76 / 11.9^{x}}$ & $\frac{2.94 \pm 0.09}{6.35 / 11.1^{x}}$ & $\frac{3.05 \pm 0.15^{\times}}{5.79 / 10.9^{x}}$ & $\frac{3.09 \pm 0.18}{7.8 / 13.4^{x}}$ \\
\hline $\begin{array}{c}\mathrm{IgA}, \\
\mathrm{mg} / \mathrm{ml} / \%\end{array}$ & $\frac{2.54 \pm 0.09}{5.09 / 9.6^{x}}$ & $\frac{1.98 \pm 0.13}{4.43 / 8.5^{\times}}$ & $\frac{2.06 \pm 0.21}{4.82 / 8.49^{\times}}$ & $\frac{2.19 \pm 0.32}{4.73 / 8.3^{x}}$ & $\frac{2.21 \pm 0.15}{4.19 / 7.9^{x}}$ & $\frac{2.24 \pm 0.42}{4.49 / 7.7^{\times}}$ \\
\hline $\begin{array}{c}\mathrm{CIC} \\
\mathrm{C} 3 \%, \\
\mathrm{mg} / \mathrm{ml}\end{array}$ & $0.22 \pm 0.05$ & $0.21 \pm 0.02$ & $0.31 \pm 0.04^{\times}$ & $0.17 \pm 0.01^{\Delta}$ & $0.06 \pm 0.01^{*}$ & $0.12 \pm 0.01^{*}$ \\
\hline $\begin{array}{c}\text { CIC } \\
3.5 \% \text {, } \\
\mathrm{mg} / \mathrm{ml}\end{array}$ & $0.09 \pm 0.01$ & $0.24 \pm 0.03^{*}$ & $0.52 \pm 0.01^{*}$ & $0.36 \pm 0.06^{\Delta}$ & $0.14 \pm 0.015^{\Delta}$ & $0.11 \pm 0.02$ \\
\hline $\begin{array}{c}\text { CIC } \\
\mathrm{C} 4 \% \text {, } \\
\mathrm{mg} / \mathrm{ml}\end{array}$ & $0.31 \pm 0.04$ & $0.3 \pm 0.01$ & $0.19 \pm 0.03$ & $0.2 \pm 0.02$ & $0.1 \pm 0.02$ & $0.17 \pm 0.01^{\Delta}$ \\
\hline $\mathrm{CIC} \mathrm{C} 4 / \mathrm{C} 3$ & $1.41 \pm 0.36$ & $1.43 \pm 0.24$ & $0.61 \pm 0.04^{\Delta}$ & $1.18 \pm 0.17^{\wedge}$ & $1.67 \pm 0.03^{\wedge}$ & $1.42 \pm 0.09^{\wedge}$ \\
\hline
\end{tabular}

Note. $\times \mathrm{P}<0.05 ;{ }^{\wedge} \mathrm{P}<0.001$; ${ }^{*} \mathrm{P}<0.0001$ relatively to the previous period.; ${ }^{\wedge} \mathrm{P}<0.0001$ relatively to 7 days; ${ }^{\mathrm{x}} \mathrm{\%} \%$ in the amount of immunoglobulins.

One day after farrow, a decrease in the amount of total immunoglobulins by $10.4 \%$ was registered in the serum of the animals; IgG - by $10.6 \%$; $\operatorname{IgM}$ - by $14.3 \%$ and $\operatorname{IgA}$ - by $22.0 \%$ due to their transudation into the mammary gland. On day 7 , the content of total immunoglobulins was by $4.5 \%$ lower than the daily value, on days 14 and 22 it increased by 8.4 and $13.8 \%$ compared to the previous indicator, and on day 26 it decreased by $5.6 \%$.

The concentration of the main isotypes of immunoglobulins in the serum of sows, starting from day 7 after farrow, tended to increase IgG by $4.3 \%$ (day 7 ), $15.7 \%$ (day 14 ), $22.2 \%$ (day 22) and $23.8 \%$ (day 26), IgM - by $5.1 \%, 6.9 \%, 10.9 \%$ and $12.4 \%$, IgA - by $4.0 \%, 10.6 \%, 11.6 \%$ and $13.1 \%$, respectively, compared to the daily rate.

The most significant increase in the content of class $G$ immunoglobulins on days 14-26 is associated with the formation of humoral immunity against vaccinations.

The dominant class in the serum of sows during lactation is IgG, the amount of which slightly fluctuated (78.9-81.1\%) (Table 1). IgG antibodies play a fundamental role in humoral immunity in case of infectious diseases, causing the death of pathogens with the participation of complement and opsonizing phagocytic cells $[15,16]$.

When determining the level of circulating immune complexes, which are the product of the reaction of antigen, antibodies and complement and play a significant role in maintaining homeostasis of the organism, an increase of the content of giant CICs $(3.0 \%)$ in the serum of sows on day 7 after farrow by $40.9 \%$ was found, and subsequently, a decrease in their concentration on days 14 and 22 by 45.2 and $64.7 \%$ and an increase on day 26 - by 2.0 times, respectively, compared with the previous indicator (Table 1).

The changes in the content of large CICs $(3.5 \%)$ were characterized by a significant increase in their concentration in animals in 1 and 7 days after farrow by 2.7 and 2.2 times; subsequently, a decrease in their level was recorded on days 14,22 and 26 by $30.8 \%, 61.1$ and $21.4 \%$, respectively, compared to the previous indicator. The number of medium CICs 
(4.0\%), starting from day 7 after farrow, decreased, and on day 26 it increased by 1.7 times compared to day 22 .

The $\mathrm{C} 4 / \mathrm{C} 3$ ratio (coefficient of pathogenicity of the CICs) on the 7 days decreased by 2.3 times, and on days 14, 22 and 26 it increased by 1.9, 2.7 and 2.3 times, respectively, compared to the indicator of day 7. The increase in the CIC C4/C3 ratio on days 14, 22 and 26 after farrow is apparently due to an increase in the antigenic load on the sows' organism associated with their immunizations against erysipelas and parvovirus infection on day 7 and against classical swine fever on day 14 .

In colostrum of sows after farrow and on the first day after delivery, the content of total immunoglobulins and main Ig isotypes was the highest as a result of their synthesis in the mammary gland and extravasation from the serum (Table 2).

Table 2. Content of total immunoglobulins, classes of immunoglobulins and circulating immune complexes in the colostrum (milk) of sows

\begin{tabular}{|c|c|c|c|c|c|c|}
\hline \multirow{2}{*}{ Indicators } & \multirow{2}{*}{$\begin{array}{l}\text { After } \\
\text { farrow }\end{array}$} & \multicolumn{5}{|c|}{ Period after farrow (days) } \\
\hline & & 1 & 7 & 14 & 22 & 26 \\
\hline $\begin{array}{c}\text { Total Ig, } \\
\mathrm{mg} / \mathrm{ml}\end{array}$ & $73.1 \pm 1.69$ & $73.6 \pm 1.81$ & $15.2 \pm 0.95^{*}$ & $12.4 \pm 0.99^{\times}$ & $11.3 \pm 0.91$ & $11.2 \pm 0.57$ \\
\hline $\begin{array}{c}\mathrm{IgG}, \\
\mathrm{mg} / \mathrm{ml} / \%\end{array}$ & $\frac{60.0 \pm 0.35}{82.1 / 83.1^{x}}$ & $\frac{60.2 \pm 0.17}{81.8 / 83.0^{x}}$ & $\frac{3.2 \pm 0.03^{*}}{21.1 / 31.1^{x}}$ & $\frac{2.6 \pm 0.05^{*}}{20.9 / 30.9^{x}}$ & $\frac{2.5 \pm 0.06}{22.1 / 32.5^{x}}$ & $\frac{2.3 \pm 0.1}{20.5 / 32.3^{x}}$ \\
\hline $\begin{array}{c}\mathrm{IgM}, \\
\mathrm{mg} / \mathrm{ml} / \%\end{array}$ & $\frac{3.19 \pm 0.06}{4.36 / 4.41^{x}}$ & $\frac{3.26 \pm 0.02}{4.4 / 4.5^{x}}$ & $\frac{1.97 \pm 0.03^{*}}{12.96 / 19.1^{*}}$ & $\frac{1.43 \pm 0.09^{*}}{11.5 / 17.0^{*}}$ & $\frac{1.21 \pm 0.08^{\times}}{10.7 / 15.7^{x}}$ & $\frac{1.14 \pm 0.03}{10.2 / 16.1^{x}}$ \\
\hline $\begin{array}{c}\mathrm{IgA}, \\
\mathrm{mg} / \mathrm{ml} / \%\end{array}$ & $\frac{9.0 \pm 0.92}{12.3 / 12.4^{x}}$ & $\frac{9.07 \pm 0.63}{12.3 / 12.5^{x}}$ & $\frac{5.14 \pm 0.041^{*}}{33.8 / 49.8^{x}}$ & $\frac{4.38 \pm 0.19^{*}}{35.3 / 52.1^{*}}$ & $\frac{3.98 \pm 0.09^{\Delta}}{35.2 / 51.8^{x}}$ & $\frac{3.67 \pm 0.12^{x}}{32.8 / 51.7^{x}}$ \\
\hline $\begin{array}{c}\mathrm{CIC} \\
\mathrm{C} 3 \% \text {, } \\
\mathrm{mg} / \mathrm{ml}\end{array}$ & $1.42 \pm 0.23$ & $2.47 \pm 0.03$ & $1.69 \pm 0.15^{*}$ & $1.56 \pm 0.09^{*}$ & $3.25 \pm 0.26^{*}$ & $2.89 \pm 0.17^{*}$ \\
\hline $\begin{array}{c}\text { CIC } \\
3.5 \% \text {, } \\
\mathrm{mg} / \mathrm{ml}\end{array}$ & $1.24 \pm 0.34$ & $1.8 \pm 0.15$ & $1.8 \pm 0.19$ & $1.4 \pm 0.09^{\times}$ & $2.2 \pm 0.19 *$ & $2.6 \pm 0.17 *$ \\
\hline $\begin{array}{c}\mathrm{CIC} \\
\mathrm{C} 4 \% \text {, } \\
\mathrm{mg} / \mathrm{ml}\end{array}$ & $1.11 \pm 0.02$ & $1.84 \pm 0.37$ & $1.0 \pm 0.11^{\times}$ & $0.89 \pm 0.09^{\times}$ & $2.65 \pm 0.43^{*}$ & $2.18 \pm 0.17^{*}$ \\
\hline $\begin{array}{c}\mathrm{CIC} \\
\mathrm{C} 4 / \mathrm{C} 3 \\
\end{array}$ & $0.78 \pm 0.1$ & $0.74 \pm 0.09$ & $0.59 \pm 0.001$ & $0.57 \pm 0.04$ & $0.81 \pm 0.06^{\wedge}$ & $0.75 \pm 0.07^{\wedge}$ \\
\hline
\end{tabular}

Note. $\times \mathrm{P}<0.05 ;{ }^{\Delta}-\mathrm{P}<0.001 ;{ }^{*} \mathrm{P}<0.0001$ relatively to the previous period; ${ }^{\wedge} \mathrm{P}<0.0001$ relatively to 14 days; ${ }^{x_{-}} \%$ in the amount of immunoglobulins.

In milk, on days 7, 14, 22 and 26 of lactation, a decrease was noted in comparison with the daily indices of the content of total immunoglobulins by 4.8 times, 5.9 times; 6.5 and 6.6 times, IgG - 18.8 times; 23.2; 24.1 and 26.2 times; IgM - by 65.5\%, 2.3 times; 2.7 and 2.9 times; IgA - by $76.5 \%, 2.3$ times; 2.27 and 2.47 times.

The dominant class in the amount of immunoglobulins in sow colostrum was IgG $(83.1 \%)$, and in milk - IgA (49.8-52.1\%) during the entire lactation period.

Secretory $\operatorname{IgA}(\mathrm{SIgA})$, supplied to the intestines of suckling piglets with colostrum (milk), protects the mucous membranes of the newborns - the main gateway for infections for piglets, playing a leading role in protecting them from viral infections [17]. SIgA is resistant to high levels of acidity and to the effects of enzymes and remains active in the gastrointestinal tract, creating a protective layer on its walls [18]. The possibility of 
formation of secretory IgA from the serum polymeric IgA entering the intestine with milk has been detected [19].

When determining the level of circulating immune complexes in the colostrum (milk) of sows, an increase in the content of giant CICs $(3.0 \%)$ by $73.9 \%$ was found one day after farrow, a decrease in their number by 31.6 and $36.8 \%$, respectively, was found on days 7 and 14, and on days 22 and 26, an increase by 2.1 and 1.9 times was found. The number of large CICs (3.5\%) increased by $45.2 \%$ in 1 and 7 days after farrow, decreased by $22.2 \%$ on day 14 , and increased by 1.6 and 1.9 times on days 22 and 26 compared to the indicator of day 14 . The level of medium CICs $(4.0 \%)$ increased by $65.8 \%$ in a day after farrow, on days 7 and 14 it decreased by 45.7 and $51.6 \%$, respectively, and on days 22 and 26 it increased by 2.97 and 2.5 times. The $\mathrm{C} 4 / \mathrm{C} 3$ ratio decreased on days 1,7 and 14 by $5.1 \%$, 20.3 and $23.0 \%$, and on days 22 and 26 it increased by $42.1 \%$ and $31.6 \%$, respectively.

An increase in the CIC pathogenicity coefficient $(\mathrm{C} 4 / \mathrm{C} 3)$ is apparently associated with a decrease in the protective properties of sows' milk, which is also indicated by a decrease in the content of total immunoglobulins their main isotypes in it.

In piglets at birth (Table 3), the content of total immunoglobulins and their isotypes $\mathrm{IgG}, \mathrm{IgM}$ and $\operatorname{IgA}$ in the serum was insignificant, due to the fact that the epitheliochorial type of the placenta in sows blocked the transfer of maternal circulating antibodies to the embryo. At the same time, IgM prevailed, with an IgM:IgG:IgA ratio of 28.9:6.7:1.

Table 3. Content of total immunoglobulins, classes of immunoglobulins, circulating immune complexes in the serum of piglets

\begin{tabular}{|c|c|c|c|c|c|c|}
\hline \multirow[b]{2}{*}{ Indicators } & \multicolumn{6}{|c|}{ Age (days) } \\
\hline & $\begin{array}{c}\text { Before } \\
\text { drinking } \\
\text { colostrum }\end{array}$ & 1 & 7 & 14 & 22 & 26 \\
\hline $\begin{array}{l}\text { Total Ig, } \\
\mathrm{mg} / \mathrm{ml}\end{array}$ & $0.3 \pm 0.01$ & $48.8 \pm 2.24^{*}$ & $41.7 \pm 0.16^{\times x}$ & $33.8 \pm 1.24^{*}$ & $29.5 \pm 0.94$ & $26.5 \pm 1.88$ \\
\hline $\begin{array}{c}\mathrm{IgG}, \\
\mathrm{mg} / \mathrm{ml} \%\end{array}$ & $\frac{0.06 \pm 0.004}{18.2 / 18.3^{x}}$ & $\frac{32.5 \pm 1.82^{*}}{66.8 / 88.1^{x}}$ & $\frac{18.3 \pm 0.95^{*}}{43.9 / 87.6^{x}}$ & $\frac{11.2 \pm 0.39^{*}}{33.1 / 89.9^{x}}$ & $\frac{8.9 \pm 0.17^{*}}{30.2 / 86.8^{x}}$ & $\frac{8.2 \pm 0.14}{30.9 / 85.4^{x}}$ \\
\hline $\begin{array}{c}\mathrm{IgM} \\
\mathrm{mg} / \mathrm{ml} / \%\end{array}$ & $\frac{0.26 \pm 0.004}{78.8 / 79.0^{\times}}$ & $\frac{1.53 \pm 0.11^{*}}{3.14 / 4.2^{x}}$ & $\frac{1.12 \pm 0.08^{\Delta}}{2.69 / 5.4^{x}}$ & $\frac{0.67 \pm 0.09^{*}}{1.98 / 5.4^{x}}$ & $\frac{0.98 \pm 0.11^{\times}}{3.3 / 9.5^{x}}$ & $\frac{1.07 \pm 0.02}{4.04 / 11.2^{x}}$ \\
\hline$\underset{\mathrm{mg} / \mathrm{ml} / \%}{\operatorname{IgA}}$ & $\frac{0.009 \pm 0.000}{\frac{1}{2.73 / 2.74}}$ & $\frac{2.84 \pm 0.15^{*}}{5.82 / 7.7}$ & $\frac{1.46 \pm 0.19^{*}}{3.5 / 7.0}$ & $\frac{0.59 \pm 0.07^{*}}{1.75 / 4.8}$ & $\frac{0.37 \pm 0.04^{\times \times}}{1.25 / 3.6}$ & $\frac{0.32 \pm 0.08}{1.21 / 3.34}$ \\
\hline $\begin{array}{c}\text { CIC } \\
\text { C3\%, } \\
\mathrm{mg} / \mathrm{ml}\end{array}$ & $0.08 \pm 0.01$ & $0.18 \pm 0.02^{*}$ & $0.27 \pm 0.02^{\Delta}$ & $0.05 \pm 0.001^{*}$ & $0.09 \pm 0.008$ & $0.08 \pm 0.01$ \\
\hline $\begin{array}{c}\text { CIC } \\
3.5 \% \\
\mathrm{mg} / \mathrm{ml}\end{array}$ & $0.1 \pm 0.02$ & $0.24 \pm 0.04^{\Delta}$ & $0.48 \pm 0.03$ & $0.05 \pm 0.06^{*}$ & $0.06 \pm 0.009$ & $0.05 \pm 0.08$ \\
\hline $\begin{array}{c}\mathrm{CIC} \\
\mathrm{C} 4 \% \text {, } \\
\mathrm{mg} / \mathrm{ml}\end{array}$ & $0.14 \pm 0.01$ & $0.21 \pm 0.02^{\Delta}$ & $0.47 \pm 0.04^{*}$ & $0.02 \pm 0.001^{*}$ & $0.03 \pm 0.006$ & $0.06 \pm 0.01^{\Delta}$ \\
\hline $\begin{array}{c}\mathrm{CIC} \\
\mathrm{C} 4 / \mathrm{C} 3 \\
\end{array}$ & $1.75 \pm 0.11$ & $1.17 \pm 0.23^{\times}$ & $1.74 \pm 0.05^{\circ}$ & $0.4 \pm 0.05^{\circ}$ & $0.33 \pm 0.08$ & $0.75 \pm 0.05^{\wedge}$ \\
\hline
\end{tabular}

Note. $\times \mathrm{P}<0.05 ;{ }^{\mathrm{P}}<0.001 ; * \mathrm{P}<0.0001$ relatively to the previous period; $\wedge \mathrm{P}<0.0001$ relatively to 14 days; $\bullet P<0.0001$ relatively to the period before drinking colostrum; $x_{-} \%$ in the amount of immunoglobulins.

In piglets at the age of twenty-four hours, as a result of absorption of colostral immunoglobulins in the small intestine, a sharp increase in the content of total 
immunoglobulins and their main isotypes $\operatorname{IgG}, \operatorname{IgM}$ and $\operatorname{IgA}$ was recorded in the serum (Table 3).

At the same time, the dominant class was $\operatorname{IgG}$, the content of which corresponded to their proportional amount in the colostrum of sows.

Subsequently, a decrease in the amount of total immunoglobulins was registered: on day 7 - by $14.5 \%$, on day 14 - by $18.9 \%$, on day 22 - by $12.7 \%$ and on day 26 - by $11.1 \%$; IgG by $43.7 \%, 38.8 \%, 20.5 \%$ and $8.5 \%$; IgA - by $48.6 \%, 59.6 \%, 37.3 \%$ and $13.5 \%$, respectively. A decrease in $\operatorname{IgM}$ concentration by 26.8 and $40.2 \%$, respectively, was recorded on days 7 and 14 and an increase in its content by $46.3 \%$ and $9.2 \%$ was registered on days 22 and 26.

The decrease in the level of immunoglobulins of all three isotypes in piglets, which was noted from day 7 of life, is associated with their catabolism and half-life, which is 2-5 days for $\operatorname{IgM}$ and $\operatorname{IgA}$ and 14-21 days for $\operatorname{IgG}[1]$.

Consequently, the passive immunity transmitted from sows to piglets by immunoglobulins from colostrum (milk) compensates for the immaturity of their immune system.

The age-related dynamics of the concentration $(\mathrm{mg} / \mathrm{ml})$ of the main immunoglobulin isotypes in the serum of piglets allows one to judge the level of colostral (lactogenic) immunity. Their absolute indicators and the ratio of the level of $\operatorname{IgG}$ to $\operatorname{IgM}$, which significantly decreased with age (on day $1-21.2: 1$; on day $7-16.3: 1$; on day $14-16.7: 1$; on day $22-9.1: 1$ and on day $26-7.7: 1$ ), indicated a decrease in passive immunity after day 14 of suckling keeping of piglets.

The registered increase in the concentration of $\operatorname{IgM}$ in the serum of piglets at the age of 22 and 26 days is apparently associated with the development of the immune system and the primary systemic immune response of animals to the microorganisms circulating in their habitat.

In the serum of piglets (Table 3 ), the dominant class is $\mathrm{IgG}$, the concentration of which changed insignificantly during the period of suckling and was 85.4-88.1\%. The IgA level decreased from $7.7 \%$ (day 1) to $3.34 \%$ (day 26), and the IgM concentration increased from $4.2 \%$ (day 1 ) to $11.2 \%$ (day 26 ), which indicated the beginning of the active immunity formation.

When determining the level of circulating immune complexes, there was detected (Table 3) an increase in the content of giant (3.0\%), large (3.5\%) and medium (4.0\%) CICs by $2.3,2.4$ and 1.5 times, respectively, in piglets at the age of twenty-four hours, compared to that one before drinking colostrum, and at the age of 7 days - by 1.5, 2.0 and 2.2 times compared to daily rates.

In piglets at the age of 14 days, a significant decrease in the content of the CICs was recorded: giant $(3.0 \%)$ - by 5.3 times; large (3.5\%) - by 9.6 and medium $(4.0 \%)$ - by 23.5 times.

On day 22, the level of CIC C3\% increased by 1.8 times compared to the indicator of day 14 , then on day 26 it decreased by $11.1 \%$, CIC $3.5 \%$ during the indicated period was almost the same $(0.05-0.06 \mathrm{mg} / \mathrm{ml})$ and $\mathrm{CIC}$ C4\% increased by 1.5 and 2.0 times, respectively.

At the same time, the coefficient of pathogenicity of $\mathrm{CIC}(\mathrm{C} 4 / \mathrm{C} 3$ ratio) in piglets at the age of 1,14 and 22 days was lower by $49.6 \%$, by 4.4 and 5.3 times, respectively, than in them before drinking colostrum, which indicated a pronounced humoral protection of animals provided by colostral (lactogenic) immunoglobulins. On days 26 , the $\mathrm{C} 4 / \mathrm{C} 3$ ratio increased by 2.3 times as compared to the indicator of day 22 , mainly due to an increase in medium-dispersed complexes, which activated complement to a lesser extent in comparison with large complexes, as a result of which they had been circulating in the blood for a long 
time, were deposited in organs and tissues, causing inflammation or suppression of immunity [10].

The registered increase in the content of medium circulating immune complexes and the coefficient of pathogenicity of CICs indicate the extinction of passive immunity in piglets, which has also been noted when determining the age dynamics of the absolute indicators of the main immunoglobulin isotypes and the IgG:IgM ratio.

\section{Conclusion}

In sows after farrowing, humoral immunity is characterized by a high content of total immunoglobulins in the blood serum, the main classes of IgG, IgM, IgA and a decrease in their concentration one day after delivery, followed by an increase during the entire lactation period. In colostrum of sows after farrowing and on the first day after farrowing, the content of total immunoglobulins and their main isotypes $\operatorname{IgG}, \operatorname{IgM}$ and $\mathrm{IgA}$ was the highest, which decreases in milk as lactation continues.

In piglets at birth, the content of total immunoglobulins and their main classes $\mathrm{IgG}, \mathrm{IgM}$ and IgA was insignificant, and at the age of twenty-four hours, as a result of absorption of colostral immunoglobulins in the small intestine, their amount in the serum was the highest, followed by a decrease in the level of IgG and IgA until the end of suckling period, and IgM - up to 14 days with a further increase in its concentration, indicating the formation of a primary immune response.

The dominant class of immunoglobulins in the serum and colostrum of sows and the serum of piglets is $\mathrm{IgG}$, and in milk - IgA.

The revealed increase in the level of medium-dispersed circulating immune complexes $(\mathrm{C} 4 \%)$ and their relation to giant (C3\%) CICs are associated in sows in the second half of lactation with an increase in the antigenic load as a result of the immunization, in milk - with a decrease in the content of the main classes of immunoglobulins, and in piglets, as a result, with a decrease in passive immunity.

\section{References}

1. Yu.N. Fedorov, O.A. Verkhovskiy, B.G. Orlyankin, T.I. Aliper, M.A. Sidorov, Veterinary medicine [Veterinariya] 6, 18-21 (2006)

2. V.I. Terekhov, A.V. Skorikov, V.N. Psiola, Veterinary pathology 2, 63-66 (2007)

3. A.F. Dmitriev, A.V. Agarkov, Fundamental researches 2, 820-824 (2015)

4. A.V. Agarkov, Bulletin of the agro-industrial complex of Stavropol 1, 69-171 (2015)

5. V.T. Samokhin, Actual problems of metabolic diseases in farm animals in modern conditions: mater. of int. scientific and practical conf., dedicated. to the $40^{\text {th }}$ anniversary of GNU VNIVIPFiT [SSI ARVRIPP\&T]. (Voronezh). 11-34 (2010)

6. Yu.G. Popov, Efficient animal husbandry 11(120), 12-13 (2015)

7. J. Žgajnar, S. Kavčič, Agronomy Research 7 (Special issue II), 775-782 (2009)

8. D. Cecchin, P.F.P. Ferraz, A.T. Campos, F.A. Sousa, P.I.S. Amaral, J.O. Castro, L. Conti, V.M.F da. Cruz, Agronomy Research 17(2), 378-384 (2019)

9. Yu.N. Masyanov, A.G. Shakhov, Reports of the Russian Academy of Agricultural Sciences 5, 40-43. (2012) 
10. Yu.V. Skibo, N.Sh. Kurmaeva, V.N. Tsibulkina, I.G. Mustafin, Z.I. Abramova, Kazan Medical Journal 94(5), 744-748 (2013)

11. I.R. Mackay, J.V. Water, M.E. Gershwin, Clin. Rev. Allegry Immunol. 18(1), 87-117 (2000)

12. R.A. Nezlin, J. Immunol.Methods 237, 1-16 (2000)

13. I.P. Kondrakhin, A.V. Arkhipov, V.I. Levchenko, G.A. Talanov, L.A. Frolova, V.E. Novikov, Methods for veterinary clinical laboratory diagnostics (M.: Kolos, 2004)

14. A.G. Shakhov, Yu.N. Masyanov, M.I. Retskiy, et al. Methodical recommendations for the assessment and correction of the immune status of animals (Voronezh, 2005)

15. B.V. Pinegin, T.M. Andronova, T.I. Yudina, International Journal on Immunorehabilitation 10, 86-89 (1998)

16. R.M. Khaitov, B.V. Pinegin, Immunology 1, 61-63 (2000)

17. B.G. Orlyankin, Proceedings of the Federal Center for Animal Health. Materials of the international scientific. conf. "Infectious pathology of animals" dedicated to the $50^{\text {th }}$ anniversary of FGU "VNIIZZh". VI, 138-144 (2008)

18. I.E. Ivanova, Health care of Chuvashiya 4, 63-71 (2015)

19. H. Salmon, Adv.Exp.Med.Biol. 480, 279-286 (2000) 